\title{
Proceso de trabajo y luchas obreras en los años '30: los trabajadores gráficos
}

\section{Labour process and struggles in the' 30s: printing industry workers}

\author{
Damián Andrés Bil ${ }^{1}$
}

Resumen: En la primera mitad del siglo XX la industria gráfica en Buenos Aires experimentó transformaciones por un acelerado proceso de mecanización. Esto se aceleró durante la década de 1930, con la incorporación de maquinaria y técnicas desarrolladas en este período. En este contexto analizamos la relación entre las transformaciones mencionadas y las luchas obreras, a partir del análisis de los conflictos que marcaron la historia de los gráficos en el período. Nuestro objetivo es develar en qué medida estos cambios determinaron el accionar de los gráficos ante esta realidad.

Palabras clave: trabajadores, proceso laboral, conflicto laboral, Industria gráfica, Buenos Aires

Abstract: In the first half of the 20th century the printing industry in Buenos Aires experienced a quickly process of mechanization. This phenomenon hastened during the decade of 1930, with the incorporation of machinery and technologies developed in this period. In this paper we analyze the relation between the transformations and the working struggles, from the analysis of the conflicts that marked the history of the graphs in the period. Our objective is analyze the effects on graphs workers in this period.

Keywords: workers, labor process, struggles, printing industry, Buenos Aires

Recibido:5 junio 2016

Aceptado: 15 septiembre 2016

\footnotetext{
* Nacionalidad: argentino. Doctor de la Universidad de Buenos Aires, mención en Historia. Investigador Asistente CONICET. Pertenencia académica: CEUR (Centro de Estudios Urbanos y Regionales). Docente de la Facultad de Filosofía y Letras (Universidad de Buenos Aires). Miembro del CEICS (Centro de Estudios e Investigación en Ciencias Sociales). Correo electrónico: damibil@gmail.com
} 


\section{1- Introducción y marco teórico}

Este artículo es parte de una investigación mayor donde estudiamos la evolución del proceso de trabajo en la rama y los conflictos en torno al trabajo de los obreros gráficos, entre 1870 y 1940, en el marco del grupo de investigación de los procesos de trabajo del CEICS. ${ }^{2}$ En este documento realizamos un recorte histórico más acotado, para analizar las relaciones entre proceso de trabajo y lucha social en la década de 1930.

La situación de los gráficos y sus conflictos laborales recibió cierta atención para el período de inicios de siglo XX y para la etapa del peronismo, ${ }^{3}$ pero tanto la situación en los años '20 como en los '30 están pendientes de un análisis. Por eso, aquí proponemos un repaso por los cambios principales en el proceso productivo en la rama gráfica en Buenos Aires, sus efectos sobre la estructura de la clase obrera y los principales conflictos al respecto. Escogemos el caso de Buenos Aires porque la capital concentraba el grueso de la producción: ya para fines de siglo XIX, contaba con las tres cuartas partes de los establecimientos del país y representaba más del 80\% del volumen de producción. En este marco, estudiamos la estructura de la rama, los cambios en el proceso productivo y laboral en la década de 1930, y reseñamos los conflictos principales protagonizados por los obreros gráficos con especial atención en la huelga de 1930. Asimismo, abordamos la relación de este fenómeno con la descalificación y el ingreso de trabajadores históricamente marginados de la rama, como mujeres y menores.

En el análisis de las transformaciones laborales nos basamos en las categorías desarrolladas por Marx 4: manufactura y gran industria, que corresponden a distintas etapas históricas en relación a la forma que asume el proceso de trabajo. La manufactura es el régimen de cooperación basado en la división del trabajo, o sea la fragmentación de tareas. El proceso para la

\footnotetext{
${ }^{2}$ Lo que dio lugar a nuestra tesis de licenciatura publicada en formato libro: Descalificados. Proceso de trabajo y clase obrera en la industria gráfica en Buenos Aires (1880-1940). Bs As, Ediciones ryr, 2007.

3Pueden verse en este sentido los trabajos de Ferrer, Nelson: Historia de los gráficos argentinos. Bs As, Dos Orillas, 2008; Badoza, Silvia: "Patrones, capataces y trabajadores en la industria gráfica. Un estudio de caso: Ortega y Radaelli, 1901-1921". Revista Secuencia, n 50, México, mayo-agosto 2001; Badoza, Silvia y Tato, María Inés: "Trabajadores y empresarios gráficos en la coyuntura crítica de 1919". X Jornadas Interescuelas Departamentos de Historia, Universidad Nac de Rosario, septiembre de 2005; Guindi, Leticia: "La huelga de los trabajadores gráficos en 1949. Análisis particular de un conflicto gremial durante el peronismo". IX Jornadas Interescuelas de Historia, Córdoba, 2003; Contreras, Gustavo: "La huelga de los obreros gráficos, 1949". I Jornadas Jóvenes Investigadores, Universidad Nac de Mar del Plata, junio de 2007.

${ }^{4}$ Marx, Karl: El capital. Bs As, Siglo XXI, 2001. Capítulos 12 y 13.
} 
producción de una mercancía se divide en un determinado número de tareas parciales. Cada paso es ejecutado por un grupo de obreros que se especializa en esa labor, con un grado de virtuosismo específico (lo que origina la división jerárquica y la escala salarial de los talleres manufactureros). Este régimen depende de la pericia del obrero parcial. Como una forma transicional, definimos manufactura moderna al régimen de trabajo asentado en la manufactura, pero que ha incorporado maquinaria en alguna de las tareas parciales, subordinada y accesoria al trabajo manual. Finalmente, nos encontramos con el régimen de gran industria al consolidarse el sistema de máquinas. De esta manera, la producción de mercancías se libera de los límites del trabajo artesanal al objetivarse su base técnica. Es decir, a partir de este momento el proceso se funda en la aplicación sistemática de la ciencia y no en el virtuosismo del obrero, como ocurría bajo los regímenes anteriores. El motor de estas transformaciones reside, a nuestro entender, en la búsqueda del capital de incrementar la productividad del trabajo, lo que ocurre en términos históricos primero con la fragmentación de tareas y más tarde con la mecanización. Esto genera la tendencia a un desplazamiento relativo de fuerza de trabajo y su conversión progresiva en apéndice de la máquina. La revolución de la base técnica tuvo efectos sobre los trabajadores y sus conocimientos que fueron bien percibidos por Braverman, ${ }^{5}$ quien planteó la teoría del deskilling. Este autor describe cómo a partir del proceso de concentración y del cambio técnico, efecto de la búsqueda del capital por conseguir menores costos unitarios de producción, el trabajo tiende en el largo plazo a simplificarse, reduciendo los conocimientos necesarios para el ingreso a las distintas ocupaciones. En ese punto, la descalificación y los cambios en el proceso laboral generan transformaciones a nivel de la estructura de la clase obrera, como ser la desaparición de los antiguos oficios manufactureros y una tendencia a la homogenización de categorías. La caída del poder del oficio y la mecanización de actividades permite que el capital incorpore a sectores antes marginados del taller, como niños y mujeres, y divida el salario anteriormente concentrado en el varón entre los distintos miembros de la familia. Esto también incidió sobre las formas de organización y el tipo de conflictos: del viejo sindicato por oficio se pasó al sindicato por rama. A su vez, las huelgas y otro tipo de acciones tendieron a unificarse y a cambiar de características. Observaremos este punto en nuestro estudio.

El proceso de investigación nos llevó a rechazar las categorías regulacionistas de "taylorismo" y "fordismo". Estos conceptos tienen la dificultad de tomar como centrales elementos que son secundarios en el proceso, como puede ser el reloj (relacionado con la organización científica de Taylor) y la cadena de

${ }^{5}$ Braverman, Harry: Trabajo y capital monopolista. México, Nuestro Tiempo, 1980. 
montaje (aporte de Ford). Al poder aplicarse estos elementos a formas de trabajo de distinta base técnica, consideramos que no son categorías de análisis adecuadas para periodizar etapas del capitalismo.

Para el trabajo utilizamos periódicos obreros y sindicales (La Vanguardia, El Obrero Gráfico), publicaciones patronales y oficiales (Argentina Gráfica - órgano de la S.I.G.A., Boletín del Departamento Nacional del Trabajo, Boletín del Trabajo, Diario de Sesiones de la Cámara de Senadores), información estadística (Censos industriales de 1935-37-39), ediciones propagandísticas (Anales Gráficos), entrevistas propias, resultados de investigaciones previas y aportes de otros estudiosos.

\section{La situación del sector en la década de 1930}

\section{Los antecedentes:}

Luego de sus orígenes en la etapa colonial, los talleres privados se multiplicaron en el período posterior a la revolución de Mayo, sobre todo en la década de 1820. De todas maneras, la industria gráfica moderna comenzó a definirse en el período final de la consolidación estatal, entre 1850 y 1860 (con imprentas como la de Casavalle, Coni, y las de otros más conocidos en la historia posterior como Kraft, Peuser, Angel Estrada, Stiller \& Lass luego Compañía Sudamericana de Billetes de Banco). Para 1879, existían en la ciudad de Buenos Aires 33 establecimientos gráficos. ${ }^{6}$ En ese entonces, la posibilidad de un trabajador de montar su propio taller era algo realizable, ya que por el bajo nivel de concentración del capital y la posibilidad de replicar el proceso de trabajo, aun regía la etapa que Marx define como de "subsunción formal" del trabajo al capital.

En las décadas siguientes, la inmigración que abasteció de fuerza de trabajo y la importación de máquinas herramientas para la actividad permitió modernizar y expandir el sector. Para fines de la década de 1880 existían 122 talleres con 1.398 obreros. La estructura de la población, mediante las medidas de educación de masas asumidas durante ese período de consolidación del estado nacional, estimuló el mercado gráfico. Además, con la mecanización se incrementó la productividad y se abarataron las mercancías. En 1887, diarios de circulación masiva como La Prensa o La Nación tiraban 18.000 ejemplares diarios, e incluso algunos en lengua extranjera como La Patria degli Italiani llegaba a 11.000. La sumatoria de las principales publicaciones alcanzaba los 110.000 números por día,

${ }^{6}$ En Chueco, Manuel. Los Pioneers de la industria nacional. Buenos Aires, Imprenta de La Nación, 1886 y Ugarteche, Félix. La imprenta argentina (1700-1929). Buenos Aires, Talleres Gráficos R. Canals, 1929. 
sin contar otras tantas que aparecían de forma periódica sobre diferentes temáticas. ${ }^{7}$ Este proceso llevó a la consolidación de grandes firmas "multigráficas" para la última década del siglo XIX. Para comienzos del siglo posterior, los diez establecimientos más importantes reunían prácticamente la mitad de la fuerza laboral gráfica de la ciudad. Es decir, un 3\% de los establecimientos contaba con el $46 \%$ de los trabajadores gráficos y el grueso de la producción. La firma más grande en 1918, la Compañía General de Fósforos, ocupaba 900 obreros gráficos e imprimía 120 millones de hojas al año. ${ }^{8}$

El ingreso de máquinas novedosas a partir de importadores, como la linotipo durante la primera década del siglo XX, permitió el aumento de la productividad (en primera instancia en los talleres de periódicos). Con ella, los linotipistas podían "parar" entre 5.000 y 8.000 caracteres por hora, frente a las 1.000 del sistema manual previo (tipógrafos). Lo mismo ocurrió con las modernas prensas y rotativas, que incrementaron la velocidad de impresión de forma exponencial. Eso se reflejó en un boom de publicaciones de todo tipo. El funcionario del departamento de Comercio de los EEUU Robert Barret, en su análisis del mercado de máquinas herramientas sostenía que antes de la Primera Guerra se imprimían alrededor de 600 publicaciones diversas en la ciudad.

\section{La industria en la década de 1930:}

Durante los años de la década de 1920, el capital se centralizó. Por ejemplo, en 1921 la Compañía General de Fósforos adquiría a Sucesores de Ricardo Radaelli, de las principales en personal ocupado y líder en la técnica del fotograbado. A su vez, las principales firmas no detuvieron su expansión. Una idea de la magnitud que podía alcanzar una gran empresa en los '20 la brinda la descripción de las instalaciones de la Cía. General de Fósforos en el barrio de Barracas en la citada obra de Ugarteche

(...) se halla instalado en un magnífico local, con una superficie de 22.000 metros cuadrados (...). Componen el establecimiento seis grandes secciones: a) de tipografía, con sus talleres de estereotipia y fotograbados; b) de litografía, con sus talleres de dibujantes y transportistas; c) de fotocromía y d) de fotogravure, ambos

${ }^{7}$ Datos del Censo General de Población, Edificación, Comercio e Industrias de la Ciudad de Buenos Aires. Buenos Aires, Compañía Sudamericana de Billetes de Banco, agosto-septiembre de 1887.

${ }^{8}$ Datos de Barret, Robert. Paper, paper products and printing machinery in Argentina, Uruguay and Paraguay. Special Agents Series $N^{o}$ 163, Washington, Department of Commerce, 1918; y del Censo General de Población, Edificación, Comercio e Industrias de la Ciudad de Buenos Aires. Buenos Aires, Compañía Sudamericana de Billetes de Banco, 1910; Tercer Censo de la República (1914). Buenos Aires, Talleres Gráficos de L .J. Rosso, 1916-17. 
con sus talleres de fotografía y retocadores; e) de fabricación de blocks para almanaques, y f) de fabricación de naipes (...). Las seis secciones cuentan con más de 500 máquinas, figurando entre ellas las más perfeccionadas y nuevas existentes en el país y emplean 1.000 obreros, dirigidos por técnicos de reconocida capacidad. Su fuerza motriz, distribuida por medio de motores eléctricos, es de $500 \mathrm{HP}$. Exceden de 200.000.000 anuales las tiradas tipo-litográficas. A estos talleres, se incorporaron en 1922 los talleres heliográficos de Ricardo Radaelli (...) que ahora funcionan refundidos con los de la calle California, donde fue trasladada la sección de rotograbado. Hagamos constar que esta sección fue, durante varios años (...) la única en la América del Sud" (p. 588)

Durante los '30, este recorrido continuó. Para 1939, en la ciudad funcionaban 983 casas, con cerca de 22.300 trabajadores. La evolución del último lustro se muestra en el gráfico 1

Gráfico 1. Establecimientos (eje derecho) y obreros y potencia instalada en HP (eje izquierdo) en la industria gráfica en Buenos Aires, 1935-1939

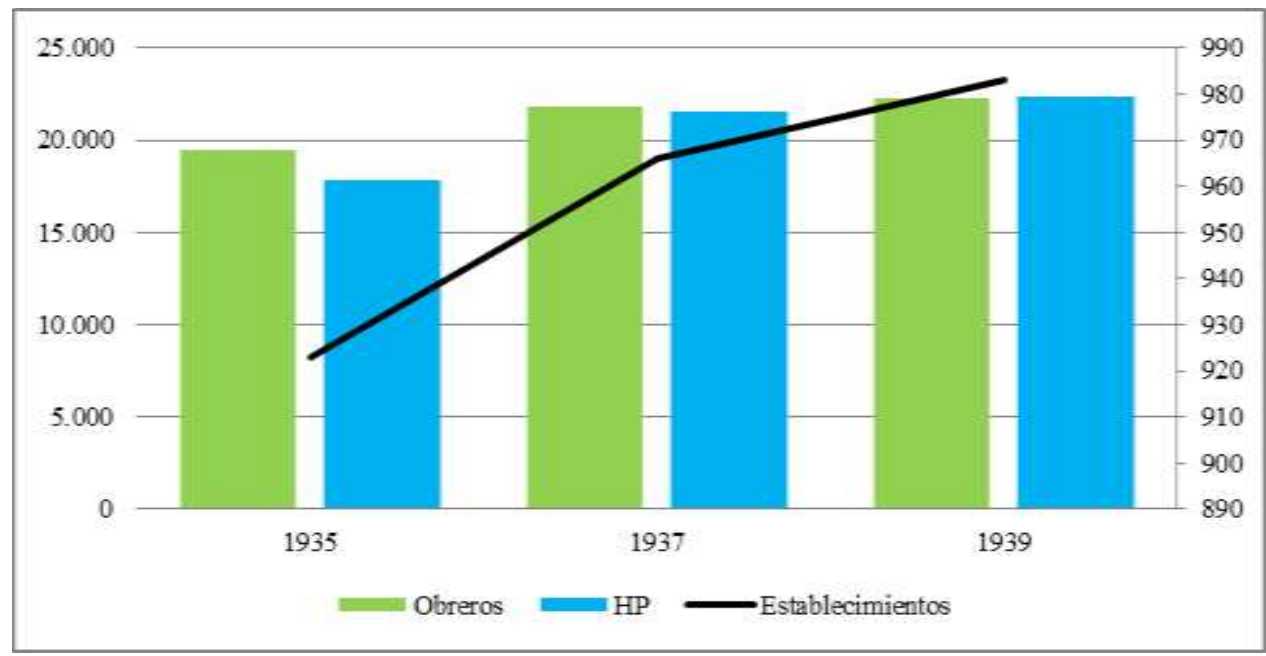

Fuente: elaboración propia en base a Censo Industrial de la República Argentina (años 1935, 1937 y 1939). Buenos Aires, Ministerio de Hacienda.

En relación al proceso de trabajo, se profundizó el desarrollo de la gran industria. Se incorporaron equipos modernos como linotipos mejoradas para la composición, máquinas impresoras, rotativas, equipos automáticos para la encuadernación y otros que mecanizaron tareas auxiliares. Asimismo, se desarrollaron novedosas técnicas que colaboraron en el proceso. Fue el caso del offset, que permitió imprimir con mayor rapidez, baratura y facilidad ciertos trabajos. O el rotograbado, que tuvo el mismo efecto en el campo de las imágenes. 
Con estos cambios, se abarató el producto y varias tareas se simplificaron. También tendió a aumentar el ritmo de trabajo, sujeto a la velocidad del sistema de máquinas. Por otra parte, vinculado con las relaciones de fuerza de la etapa, el salario tendió a estancarse a pesar del aumento en la productividad. ${ }^{9}$ Veamos en detalles estos cambios y la reacción de los trabajadores.

\section{Los cambios en el proceso de trabajo durante los años '30}

La linotipo revolucionó el proceso laboral a comienzos de siglo XX, ya que mecanizó la composición (la tarea de armar las líneas de caracteres que luego pasaban a la impresión). Durante las décadas posteriores, la introducción de diferentes máquinas ahondó el proceso general. El régimen de gran industria se consolidaba. Los '30 vieron acentuarse este desarrollo: las máquinas fueron mejoradas, y a su vez se redujo el papel del obrero. Esta década fue prolífica en la incorporación de equipos. En publicaciones especializadas de la época, como en Anales Gráficos (del Instituto Argentino de Artes Graficas) podemos ver publicidades de máquinas modernas ofrecidas por las casas importadoras. La opinión de un columnista del sindicato nos brinda un panorama acerca del masivo ingreso de maquinaria:

[...] Las linotipos, las Thompsons, las Ludlows, las monotipos son otros tantos aliados que enriquecen al industrial. [...] Y ahora viene lo gordo: las máquinas impresoras. Pasó el tiempo del pedal y se transformó la especialidad. Vinieron las planas, las automáticas, las rotativas de altas velocidades, las de doble revolución. [...] ¡Triste desilusión, por cierto, para nosotros los gráficos que hemos podido comprobar la falange de desocupados en nuestra secretaría [...]! La más castigada de todas las grandes ramas ha sido la encuadernación, que por fatal destino siguió el curso trazado por las ramas madres. Aquí también apareció la moderna guillotina automática, la numeradora rápida, la dobladora que no sólo dobla sino que también cose. [...] Venga ahora la litografía. Allí también hizo su aparición la moderna maquinaria, la planeta, por ejemplo, a colores, que abarató la mano de obra. Y para qué seguir, si sería descubrir en cada una de las cien especialidades el mismo resultado!10

Como menciona el columnista, modernas máquinas entraron en las secciones fundamentales. En la composición, área donde se armaba el texto, se perfeccionaros las máquinas linotipos. Las linotipos funcionaban bajo el principio

${ }^{9}$ En base a Ferreres, Orlando: Dos siglos de economía argentina. Bs. As., Fundación Norte y Sur, 2009.

${ }^{10}$ El Obrero Gráfico, no 258, mayo de 1936, p. 6. 
de la máquina de escribir: el linotipista se sentaba frente a un teclado para confeccionar las líneas. Cuando la linotipo ingresó, desplazó en gran medida a la composición manual. Subsistieron tareas que debían realizar los tipógrafos a mano, como títulos, caracteres especiales, arreglo de la página, entre otras. Durante los '30 se fabricaron nuevos modelos con agregados. Las nuevas avanzaron sobre las acotadas labores manuales que se realizaban para completar el trabajo de composición. Las máquinas mejoraron su capacidad al punto de reemplazar en gran medida a la tipografía:

Las máquinas de componer y fundir líneas [...] han llegado a apoderarse no sólo de la composición de revistas y obras corrientes, sino incluso las de más difícil ejecución tipográfica, como por ejemplo: catálogos, listines telefónicos, diccionarios, anuarios, libros científicos, etc. Tanto es así que estas máquinas, en cuanto a su construcción actual, difícilmente puedan ser superadas. ${ }^{11}$

Las nuevas linotipos incorporaban funciones que facilitaron la labor: ahora podían hacerse tareas otrora reservadas a trabajadores manuales calificados, como centrado del texto, caracteres especiales, etc. Con estos adelantos, la composición mecánica avanzó sobre los nichos que mantenía la manual. La tarea del tipógrafo se restringió al armado de páginas y a la corrección. El trabajo se descalificaba a medida que avanzaba su objetivación.

Otro tanto ocurrió con la impresión, donde con los productos de la composición se imprimía el texto. Nuevas máquinas simplificaron tanto las tareas centrales como las auxiliares. Eso se tradujo en una mayor descalificación de los impresores. Algunas novedades fueron la mejora del sistema de entintado y los dispositivos para la alimentación de páginas. Una publicidad de un importador nos brinda los detalles técnicos de la Planeta de 1938, una de las más utilizadas:

El nuevo modelo [...] tiene tambor intermitente y salida frontal de los pliegos que se efectúa por medio de pinzas montadas sobre cadenas. La recepción de los mismos se realiza en cajones que se pueden cambiar durante la marcha. Asimismo, también viene equipada de un dispositivo semiautomático para intercalar. La accesibilidad a esta nueva "Planeta" es notable: su altura es tal que el obrero no necesita montar sobre estribos o bancos para llegar a cualquier parte de la misma. [...] En lo que respecta al ponepliegos, es Original Universal [...].12

\footnotetext{
${ }_{11}$ Anales Gráficos, no 12 Año XXII, diciembre de 1931, p. 16. También en Ídem, nº 8 Año XXVIII, agosto de 1936, pp. 4-5.

${ }^{12}$ Argentina Gráfica, no 25 Año III, julio de 1938, p. 24 (el subrayado es nuestro).
} 
Obsérvese que las "bondades" resaltadas por el importador están relacionadas con la automatización de los pasos necesarios para la impresión: la alimentación del papel por ejemplo. Esto reducía la tarea de los ayudantes. En las rotativas, máquinas que imprimían sobre una bobina de papel en continuo giro (por lo general para diarios), se les anexó una dobladora automática que entregaba los periódicos listos para el despacho, entre otras modificaciones. Durante esta década, los principales como La Nación y La Prensa adquirieron rotativas de última generación. Un visitante de las instalaciones de este último detallaba las características:

En su interior, extendiéndose a casi todo lo largo del edificio, a un costado, surgiendo de los cimientos del subsuelo por el piso de la planta baja, se levanta la poderosa rotativa. Las 21 unidades dobles están divididas en series de tres, y cada serie posee una dobladora doble, tipo Super Producción, que dobla y empaqueta en montones de 50 ejemplares los diarios, sirviéndolos ya completamente listos para ser presentados al lector, mientras los demás continúan pasando a toda velocidad por los entintados cilindros de la máquina [...]. La rotativa mide en total unos 46 metros de largo y pesa 625.000 kilogramos. Está compuesta por 175.000 piezas distintas y funciona impulsada por 56 motores, con un total de 1.250 caballos de fuerza. Su capacidad máxima de consumo es de 70.000 kilogramos de papel por hora. La gran rotativa tiene una velocidad mínima capaz de producir 840.000 ejemplares por hora de un diario de 12 páginas, reduciéndose el número de ejemplares de producción proporcionalmente al aumento de páginas de la edición. ${ }^{13}$

La descripción es impactante: una mole de casi media cuadra y de 625 toneladas impulsada por 56 motores, lanzando 14.000 diarios de doce páginas por minuto. Llama la atención la ausencia de obreros en la crónica. La objetivación del trabajo en este aspecto estaba avanzada. En cuanto a las minervas, para trabajos de pequeño formato, la alemana Heidelberg inventó un modelo completamente automático, desde la alimentación a la presión de la bandeja de impresión, con una velocidad de 4.600 pliegos por hora. ${ }^{14}$ La tarea del minervista quedaba reducida al control de la máquina y al ajuste previo del equipo para el trabajo. Otro ingreso fue el de las impresoras offset. El offset parte del principio de la litografía, técnica de impresión mediante piedras con relieve que transmitían la imagen al papel a partir del rechazo entre el agua y el aceite. En las offset una plancha entintada se estampa sobre un cilindro de caucho que reporta esta impresión al papel, mediante una

${ }^{13}$ En Anales Gráficos, n 7 Año XXVI, julio de 1934, p. 9. La incorporación de linotipo en el otro diario en La Nación: Un siglo en sus columnas. Buenos Aires, La Nación, enero de 1970, pp. 154-155.

${ }^{14}$ Argentina Gráfica, no 1 Año 1, diciembre de 1935, p. 20. 
combinación de superficies cubiertas de agua y otras de un compuesto oleoso. La técnica había sido descubierta en 1904, pero su aplicación recién se masificó en los '30, cuando se aplicó a la impresión de textos. Permitió así una considerable baja de los costos de producción al eliminar pasos intermedios que precisaban las máquinas tradicionales. Nuevamente en una edición de Anales Gráficos ( ${ }^{\circ}$ 6, Año XXV, junio de 1934, p.2), un analista se jactaba de haber previsto la difusión de esta técnica con anticipación

[...] profetizando el avance del offsismo en el campo de la impresión tipográfica, puse en alarma a los impresores de plana contra la nueva enemiga. [...] los hechos nos han dado la razón. Las offset se multiplican en todas partes y salen hacia el cielo los quejidos de los pobres impresores clásicos que ven al colega de enfrente, que cuenta con una o más máquinas offset, quitarles los trabajos de las manos, pues presenta presupuestos terroríficamente bajos dado que no pone en cuenta, por no necesitarlos, clisés, estereotipias, desgaste de tipos, ni siquiera papeles especiales para fotograbado. [...] Se producen revistas "maravillosas", de precio ínfimo y con páginas e ilustraciones en negro y en colores. Todo el mundo puede hoy adquirir revistas de doscientas y más páginas, impresas en negra y policromadas, al precio modesto de veinte centavos. Y esto debido a la intervención de la offset.

Para ciertas impresiones, el offset eliminó una serie de pasos sin resentir el tiraje. El bajo costo de la producción permitió la difusión de una serie de publicaciones a precios accesibles. En poco tiempo se fabricaron equipos para imprimir a dos colores a gran velocidad y se anexaron dispositivos para alimentar o extraer el papel:

El ponepliego independiente, lleva las hojas al sistema de guías graduables en todas direcciones $\mathrm{y}$, una vez en posición de registro, los pliegos pasan a las pinzas del tambor $\mathrm{y}$, ya impresos, la cadena de pinzas con dispositivos especiales de soplamiento y de succión los va amontonando con perfecta simetría. La máquina va provista de un automático, que levanta la presión cuando una hoja falta o entra torcida, y para, a la vez, la distribución del agua y de la tinta, siguiendo la marcha normal al entrar un nuevo pliego. La tinta y el agua son reguladas por el operario con escalas a la vista, sin que tenga que moverse de su sitio. ${ }^{15}$

Aquí también se simplificaba el trabajo al mecanizarse la mayor parte del proceso. La tarea del operario era la correcta colocación del molde para imprimir.

${ }^{15}$ Anales Gráficos, no 2 Año XXII, febrero de 1931, p. 15. 
Esto requería cierto entrenamiento como maquinista, pero menor que en tiempos anteriores cuando el resto de los pasos eran manuales. Una vez en funcionamiento la máquina, la tarea del obrero se reducía al mero control.

En las secciones relacionadas con la producción de imágenes el cambio más importante fue la difusión del rotograbado. La técnica permitía la reproducción directa de la fotografía en el texto, sin los pasos intermedios que demandaban técnicas como el fotograbado. ${ }^{16}$ Con ello se lograba una calidad superlativa de imagen, con gran nitidez de las tonalidades. Se difundió de manera industrial a fines de los '20. Con los primeros equipos, los diarios consiguieron publicar las noticias de última hora con imágenes recientes, confeccionar suplementos ilustrados, revistas y libros de gran calidad visual.

La última de las grandes secciones de la rama es la encuadernación. Hacia mediados de los años '20 se encontraba avanzada la mecanización. Existían máquinas de coser con hilo o metal, que podían alcanzar las 250 costuras por minuto; dobladoras de pliegos semi-automáticas y modernas guillotinas. Pero las labores manuales persistían: el doblado de los pliegos, la compaginación correcta y el pegado de tapas (que formaban parte del estilo denominado rústica). Y no necesariamente por la inexistencia de máquinas: en talleres pequeños e incluso medianos, o para tiradas reducidas, muchos industriales optaban por emplear obreros (niños o mujeres) para realizar estos pasos. Ello se debía a que para tiradas chicas les resultaba más económico abonar bajos salarios que adquirir un equipo de lenta amortización. Las fábricas más grandes incorporaron maquinaria aquí desde fines de los '20. Luego las siguieron otras empresas. Un ex doblador de una imprenta mediana que trabajó en esa década nos expuso la evolución del encuadernado en general, y en su lugar de trabajo en particular:

En la encuadernación había que formar los folletitos, encuadernar los libros, pegar la tapa de cuadernillos. Eran tareas manuales. [...] La dobladora era automática, era la máquina Brehmer con el aparato Rotary que abastecía el papel, e iba pasando el pliego de uno a uno y salía doblado en $8,16,32$ páginas. [...] Después pasaba a la guillotina que hacía el refilado. Los cambios se iban produciendo a medida que aparecían máquinas nuevas, nueva tecnología que suprime mano de obra. Por ejemplo entró una máquina que pegaba la tapa del libro encuadernado, y ya salía refilado listo el libro para la venta. Era la máquina de rotobinder, había varias máquinas según el

\footnotetext{
${ }^{16} \mathrm{El}$ rotograbado permitía la impresión de imágenes desde un cilindro de diversos metales, donde se grababa en relieve la imagen a reproducir. Este proceso no solo aumentó la calidad, sino que eliminaba los pasos intermedios del fotograbado, que requería del tratamiento de la imagen sobre películas y procesos posteriores sobre la placa de impresión.
} 
fabricante. ${ }^{17}$

Si bien varias continuaron con el método manual, el grueso de la producción provenía de las grandes fábricas, que mecanizaban progresivamente. El ritmo de producción y la demanda así lo exigían. A mediados de los '30 las innovaciones del encuadernado simplificaron la labor. Un ejemplo lo brinda el ingreso de nuevas guillotinas, como las Nebiolo italianas. Mediante un sistema de presión automático eliminaban la necesidad de regular manualmente la fuerza: directamente se presionaban botones en un tablero para accionar una cuchilla que efectuaba 40 cortes por minuto. ${ }^{18}$ Hacia finales de la década, un encuadernador activista reflexionaba con amargura

El oficio de encuadernador se divide, digamos así, en tres especialidades. La de encuadernadores de la "guardia vieja", [...] en libros con banda, álbumes y protocolos; la otra, la de los prácticos de la rueda, de los libros en blanco, copiadores, tapas de tela, carpetas y carnets, y la tercera la de los "craks" en talonarios y blocks, revistas y folletos, cuadernos y libretas. [...] Los encuadernadores de la "guardia vieja" ya han sido casi totalmente desplazados [...] ¿Y qué decir de la tercera especialidad? Esta es en la actualidad la más numerosa y está compuesta por obreros y obreras jóvenes, cuyos salarios son tan bajos [...] que constituyen una verdadera vergüenza para el gremio gráfico. La tragedia de este sector es todavía más evidente, porque ni aprender más el oficio pueden, ya que la racionalización capitalista va haciendo del obrero, de más en más, un simple complemento de la máquina $[\ldots] \cdot 19$

Mecanización creciente, disminución del conocimiento necesario, desarrollo de la gran industria con el obrero como "apéndice" de la máquina y estancamiento salarial. Se repite la situación en el resto de las secciones. El avance de la gran industria provocó cambios en la estructura de la clase. Asimismo, estableció la posibilidad para el capital de avanzar con mayor velocidad sobre las condiciones de trabajo.

\footnotetext{
${ }^{17}$ Entrevista a A.C., ex doblador, febrero de 2007, en poder del autor. La empresa en la cual se desempeñó fue la Imprenta López, que contaba con cerca de 120 obreros para el período según el entrevistado. ${ }^{18}$ Anales Gráficos, no 25 Año Tercero, julio de 1938, p. 25.

${ }^{19}$ El Obrero Gráfico, no 285, noviembre diciembre de 1939, p. 14.
} 


\section{Los efectos sobre la clase obrera y sus formas de lucha}

\section{Mujeres, niños, cambios productivos y conflictos parciales:}

Las innovaciones tuvieron sus consecuencias sobre la clase obrera. Consideramos que el fenómeno más importante fue la tendencia a la descalificación del trabajo, como señalamos previamente. En la etapa de la manufactura, el aprendizaje de tareas, al no existir un sistema formal de enseñanza para las mismas, se realizaba en los establecimientos. Por ello, los trabajadores calificados de oficio mantenían el control del ingreso, ya que decidían cómo y a quién enseñar. En la composición por ejemplo, la labor de tipógrafo que ordenaba los caracteres de forma manual, requería un largo aprendizaje de años que se realizaba en el taller. Pero con la máquina las tareas se simplificaron. El aprendizaje perdió gran parte de su peso como regulador del ingreso a las tareas. ${ }^{20}$ En este sentido, en 1924 la Federación Gráfica informaba con resignación

Nuestros asociados, no siendo tipógrafos, no pueden practicar la linotipo, por impedirlo el reglamento de trabajo. Y sin embargo continuamente nuestro sindicato se ve obligado a aceptar el ingreso de obreros que han aprendido la máquina al margen de la organización [...]. Debe [...] ser suprimido el artículo pertinente, y dar libertad a los obreros [...] que quieran aprender el manejo de las máquinas de componer. ${ }^{21}$

El sindicato reconoció así la pérdida del control del aprendizaje. Hacia finales de la década del '30 se sumó a este fenómeno la afluencia de linotipistas del interior hacia la capital. Empleados en jornadas agotadoras con salarios miserables, según el sindicato desplazaron a muchos linotipistas locales. En otras secciones observamos fenómenos similares, como ya reseñamos.

Otro elemento para dar cuenta del proceso de descalificación era el desconocimiento del sistema de categorías fijado por convenio colectivo. Las mismas establecían las tareas a realizar por cada operario según su nivel de conocimientos. Con los cambios en el proceso de trabajo, la histórica separación en categorías perdió fundamento técnico. Por lo tanto, en reiteradas ocasiones los industriales ocupaban obreros de categoría inferior en tareas restringidas a "oficiales". Con ello, pagaban una tarifa menor por el mismo trabajo. El fenómeno

\footnotetext{
${ }^{20}$ Para mayor información sobre el tema del aprendizaje ver Badoza, Silvia: "Typographical Workers and their Mutualist Experience: The Case of the Sociedad Tipográfica Bonarense, 1857-80", en Adelman, Jeremy (comp.): Essays in Argentine Labour History, 1870-1930. Londres, Macmillan Press, 1992.

${ }^{21}$ El Obrero Gráfico, no 145-46, febrero-marzo 1924, p. 2. También en no 270, febrero 1938, pp. 12-13.
} 
lo registramos desde la primera década del siglo XX, pero en los años '30 se agudizó. Era común lo que denunciaban los obreros de la imprenta López, donde "se ha venido despidiendo a viejos operarios oficiales remplazándolos [...] con medios oficiales, a quienes [...] se paga un salario inferior" ${ }^{22}$ Esta situación se repetía en varios, como en Hays Bell y Cía., donde obreros "ayudantes" con un sueldo menor realizaban tareas reservadas a operarios de categoría superior. Este desconocimiento de las categorías se relaciona con el problema de la polifuncionalidad, la realización de dos o más tareas de forma simultánea por un mismo operario, y con la rotación de obreros por distintos puestos. Dada la simplificación de tareas, en poco tiempo el obrero estaba apto para realizar varias funciones. Si bien el convenio especificaba tareas puntuales por operario, era común que se intercambiara a los obreros entre diferentes secciones. El sindicato intentó limitar esta situación en los establecimientos donde tenía peso, precisamente los más grandes. No obstante, fue durante estos años una preocupación latente para los trabajadores.

La creciente mecanización permitió a los industriales ocupar mujeres y niños. Ello debido a que el ingreso de máquinas permitía incorporar trabajadores con menor fuerza física. A su vez, con la simplificación de tareas, pueden ocuparse sectores históricamente marginados de la actividad como en este caso niños y mujeres. Esto tiene a nuestro entender dos consecuencias. A nivel económico, la baja del salario, puesto que el sustento de la familia representado anteriormente en el salario del varón se fragmenta entre los diferentes miembros de la familia. En nuestro caso particular, también permite al industrial disponer de trabajadores con escasa formación sindical. En una rama donde existía un sindicato fuerte como la Federación Gráfica, con influencia socialista y sindicalista, esto no era un detalle menor. La organización de mujeres y niños le llevó sus años y esfuerzos considerables a los gráficos. Era una tarea de primera importancia, dado su avance en la rama. El trato por lo general era pésimo, con denuncias de acoso incluidas. Un activista comentaba la situación de las obreras:

[...] la mujer obrera es la que está en condiciones más inferiores, en lo que se refiere a salarios, trato, etc., [...] en los lugares de trabajo. [...] cada vez más, la obrera gráfica representa ser una competidora seria al trabajo de los hombres; aprovechada ésta por los patrones, pagando salarios más bajos $y$, en consecuencia, obteniendo mayor ganancia. [...] debido a que no están organizadas sindicalmente la mayoría, se les paga $\$ 1.20$ y $\$ 1.80$ por día". 23

${ }^{22}$ El Obrero Gráfico, no 232-33, agosto - septiembre de 1933, p. 3.

${ }^{23}$ El Obrero Gráfico, n² 282, junio de 1939, p. 12. Y en ídem, n² 256, febrero y marzo de 1936, se denunció el colmo del maltrato: en la Fabril Financiera (ex General de Fósforos), un capataz jefe retiró las puertas de las letrinas para vigilar que las obreras no tardaran mucho tiempo con sus 
En esta declaración observamos cierta tensión en los activistas del sindicato, como contradicción interna, en torno a la cuestión del trabajo femenino. Antes, los gráficos habían resistido el ingreso de la mujer. Adoptaron hacia inicios de siglo XX una posición reaccionaria. Posteriormente, cuando se convirtió en un hecho, se dispusieron a organizar a las nuevas compañeras. No obstante, y a pesar de estos intentos de sindicalización, persistía aun cierto resquemor al ingreso de la mujer como lo muestra la precedente cita de finales de la década de 1930. En cuanto al trabajo efectivo de menores y mujeres, en ocasiones las mayores exigencias de los industriales derivaron en resultados fatales, como la muerte de un menor de 14 años al accidentarse en una máquina de barnizado. ${ }^{24}$ Ante estos hechos el sindicato redobló los esfuerzos de organización. Se hicieron comunes en el periódico las interpelaciones a la mujer gráfica, exigiéndole la afiliación. Asimismo, en el caso del incumplimiento de categorías o por rotación del personal, peticionaron ante el Departamento Nacional del Trabajo o llegaron a producir conflictos parciales. Pero no fueron estos los únicos desafíos que enfrentaron en el período. Existieron otros problemas, como los salarios por debajo de la tarifa y las malas condiciones. En este aspecto fueron mayores las intervenciones de la Federación. En relación a los salarios, encontramos conflictos en talleres pequeños y medianos como la Casa Nagel y Muzkat y Zaslavsky, pasando por empresas periodísticas como el diario The Standard, hasta grandes fábricas como la firma Kraft. En cuanto a las reivindicaciones de condiciones laborales, tuvieron siempre un papel destacado en la agenda del sindicato. Las estrategias de la patronal en casas como Kraft sirven de ejemplo para mostrar la situación con la cual se enfrentaban los gráficos. En septiembre de 1937, el sindicato denunciaba que la empresa hacía trabajar a sus obreros doce horas, con una paga inferior, incluso en días festivos y domingos sin descanso compensatorio. Para eludir las inspecciones del Departamento del Trabajo, había ideado un sistema de alarmas interno para avisar de la presencia de inspectores. De esa forma, se daba la orden de retirar a los obreros en infracción, es decir a los que habían superado la jornada legal, por unas puertas laterales. No era la única "precaución" de los industriales: si la inspección bloqueaba las puertas, se escondía a los obreros en un departamento contiguo a la fábrica, alquilado a tal efecto. No faltaron ocasiones, según el sindicato, en las cuales la huída precipitada de obreros ante los inspectores provocó "la alarma en todo el barrio".

La crisis del '30 afectó a los trabajadores del sector. El sindicato denunciaba licenciamientos y suspensiones por la baja temporaria de la actividad. Aproximadamente hasta 1933, el sindicato mantuvo una estrategia defensiva.

necesidades, realizando estas a la vista del resto del plantel.

${ }^{24}$ La información sobre trabajo femenino e infantil corresponde a El Obrero Gráfico, $\mathrm{n}^{\circ} 237$ (enero de 1934), $\mathrm{n}^{\circ} 266$ (septiembre de 1937), $\mathrm{n}^{\circ} 269$ (enero de 1938), $\mathrm{n}^{\circ} 271$ (abril de 1938). 
Salvo contadas excepciones (como en Isidoro Moggio o en la Sociedad Impresora Americana durante marzo de 1930), la organización priorizaba el acuerdo sin llegar a la huelga. Luego de 1933, con la recuperación de la actividad, hubo mayor cantidad de conflictos que terminaron en huelgas parciales. En ciertos casos, declaradas por las bases antes que el sindicato interviniera. Una vez declaradas, por lo general recibían la aprobación de la Federación Gráfica. Así sucedió en la empresa Hays Bell en marzo de 1938, en una huelga declarada por sus obreros contra los bajos salarios, malas condiciones de trabajo e higiene y suspensiones injustificadas. ${ }^{25}$ En la segunda mitad de la década también se intensificaron los esfuerzos de organización: a partir de 1935 se acentuó la agitación de las diferentes comisiones de sección para aumentar el número de afiliados. Por último, en estos años hay dos movimientos que se convirtieron en generales: la huelga de 1930 por las 36 horas semanales en ramas insalubres, y la huelga de 1936 por mejora salarial.

\section{La huelga de 1930}

El saturnismo, la enfermedad profesional más extendida, siempre fue una preocupación para los gráficos. La intoxicación crónica era incurable y podía producir la muerte. Sus efectos se extendían más allá del enfermo, transmitiendo el efecto a su pareja en muchos casos. Los estudios concluían que el peligro máximo residía en el aire contaminado con polvo o vapor de plomo. El saturnismo estaba extendido entre los tipógrafos, quienes solían colocarse los caracteres en la boca para acelerar las tareas. También el residuo plúmbico ocasionado por el desgaste de los tipos intoxicaba los ambientes de trabajo. Durante las primeras décadas del siglo XX, el ingreso de máquinas que fundían plomo acentuó el problema y lo extendió. Así, el saturnismo afectó principalmente a trabajadores de linotipo, de rotograbado, de aerografía y de dorado. En un estudio efectuado para la Facultad de Derecho, publicado en Anales Gráficos ( $n^{\circ} 1$ Año XXI, enero de 1930) se afirmaba

[...] lo que caracteriza la gravedad del trabajo de que me ocupo es la intoxicación frecuente en los cajistas y linotipistas por el polvo de plomo y sus emanaciones y vapores que penetran en el organismo, en pequeñas cantidades y que no son advertidas sino cuando existe una perturbación seria [...] cuando ha aparecido el saturnismo, enfermedad profesional que es un verdadero flagelo. En los locales de las imprentas cuya ventilación es deficiente, se ha examinado el polvo de la atmósfera y se ha comprobado que hay suspendido en el aire [...] hasta un 10 por ciento de plomo que los obreros respiran, intoxicándolos lentamente. [...] El agente de la intoxicación es el polvo o el

${ }^{25}$ Idem, no 271, abril de 1938, p. 16. 
vapor que despide el plomo en estado de fusión. [...] En mi inspección a las imprentas de Buenos Aires, he podido observar que el peligro del saturnismo, entre nosotros, es de la misma gravedad para tipógrafos y linotipistas. (p. 32)

Médicos laboralistas apoyaban el estudio con más datos sobre la forma de intoxicación:

En cuanto a los linotipistas se contaminan fácilmente por otro mecanismo [...] la industria moderna usa las llamadas máquinas linotipos. [...] es necesario recordar que la mezcla de plomo es fundida por la misma máquina en crisoles eléctricos a determinada temperatura, que sería de $180^{\circ}$ a $\operatorname{los} 300^{\circ}$ grados centígrados, según los distintos tipos. Teóricamente, la temperatura de volatilización del metal llegaría a los $500^{\circ}$, que serían los necesarios para su evaporación. No obstante, en la práctica se han captado cantidades de plomo dosable en los ambientes cercanos a las máquinas linotipos [...]. La absorción puede ser tolerada durante mucho tiempo sin que el organismo manifieste su presencia. ${ }^{26}$

Las medidas profilácticas sancionadas en el convenio colectivo de 1928, la provisión por parte de los industriales de mascarillas y de un litro de leche diario para cada linotipista y la instalación de dispositivos para mejorar la circulación del aire, no eran suficientes para controlar la enfermedad. Además, según el informe citado, varias casas desconocían las precauciones ya que implicaba a su juicio gastos improductivos. Un evento modificó la situación a comienzos de la década del '30. Nos referimos a la sanción de la ley 11.544 de septiembre de 1929. La misma habilitó el reclamo por la jornada de 6 horas para las secciones insalubres. Ello reavivó el interés del gremio por el problema del saturnismo. Con la sanción de la ley, el sindicato organizó una solicitud y presionó ante el congreso y el Departamento Nacional del Trabajo para lograr que se declararan insalubres las áreas que manipulaban plomo. En marzo el sindicato se organizó para conseguir las 6 horas en las secciones de composición, rotograbado, dorado y plateado. El estado público del movimiento propició la intervención del Departamento del Trabajo y del Departamento Nacional de Higiene. Ante ello, en mayo los industriales elevaron un petitorio al ministro del interior para que no se aplicara la medida. Alegaban que sus locales reunían las condiciones higiénicas para operar con la jornada de ocho horas. Buscaban evitar la reducción del horario que no se

\footnotetext{
${ }^{26}$ Idem, no 12 Año XXX, diciembre de 1939, pp. 3-4 (subrayado en el original). Asimismo, un ex impresor nos ha manifestado como adquirió un principio de intoxicación al operar su máquina detrás de una linotipo que despedía constantemente los vapores de plomo fundido (entrevista a A.N., ex impresor de taller pequeño, 19/03/2007, en poder del autor).
} 
correspondía con una rebaja proporcional del salario. Para demorar el trámite, encargaron a dos médicos un informe sobre el estado de cinco locales con 83 obreros, que "resultó" favorable a sus intereses. ${ }^{27}$ No obstante, la presión de los obreros obligó a ciertos industriales a otorgar la jornada de 6 horas, aunque la mayoría no cumplía con la reglamentación. Asimismo pretendían desconocer el derecho de los obreros de composición a la jornada reducida. En junio la mayor parte de la patronal resolvió otorgarlas, pero también se dispuso a reducir el salario proporcionalmente. Ante ello, el 16 de julio el sindicato declaró la huelga de las ramas insalubres. Luego llegó la solidaridad del resto del gremio. El conflicto se concentró en las empresas más importantes como Peuser, Kraft, Rosso y la Fabril Financiera. Los industriales recurrieron a la policía: oficiales de comisarías cercanas a las fábricas hostigaban continuamente y detenían a los huelguistas. ${ }^{28}$ También reclutaron crumiros. Esto ocasionó roces con el resto de sus planteles en actividad, como ocurrió con la Fabril Financiera y con los litógrafos de Peuser a quienes se los quería utilizar para trabajos de otras casas. Estos se plegaron a los huelguistas en apoyo de su reclamo. Numerosos sectores de la clase, de diferentes puntos del país, se solidarizaron con los gráficos.

La patronal atacó con un comunicado donde sostenía que la Federación hacía una interpretación "antojadiza" de la ley. Las empresas buscaban todas las formas posibles de vulnerar la medida. Un caso extremo fue el de la Fabril Financiera: el sindicato denunció que dicha compañía instó a sus obreros jubilados a presentarse al trabajo bajo amenaza de suspender el pago de la pensión. ${ }^{29}$

A pesar de estos ataques, la solidaridad del gremio se mantuvo. La Federación sostuvo los ingresos del fondo de huelga con aportes diversos. Para agosto, comenzó a notarse la falta de publicaciones periódicas. La Fabril Financiera intensificó el reclutamiento de carneros, mientras desprestigiaba públicamente a los huelguistas. Los obreros respondieron a la provocación con un arma histórica: el boicot. En su asamblea del 21 de agosto resolvían:

[...] considerando que la Compañía Fabril Financiera es la que encabeza la reacción patronal tendiente a la no implantación de la jornada de seis horas para las ramas insalubres, resuelve: autorizar a la comisión general administrativa la inmediata aplicación de boicot para todos los productos de

\footnotetext{
${ }^{27} \mathrm{El}$ reclamo obrero aparece en Boletín del Departamento Nacional del Trabajo, $\mathrm{n}^{\mathrm{o}}$ 152-3-4, octubrenoviembre-diciembre de 1930, p. 3329. El estudio encargado por los patrones es firmado por los Dres. Gandolfo y Zwanck. En La Vanguardia 16/4/1930, p. 4 y en Boletín del Departamento Nacional del Trabajo, $\mathrm{n}^{\circ}$ 152-3-4, octubre-noviembre-diciembre de 1930, p. 3331.

${ }^{28}$ La Vanguardia, 22/7/1930, p. 5. También en Idem, 2/8/1930, p. 4: los huelguistas denunciaban a los comisarios de las dependencias 11 y 22 de la policía porteña.

${ }^{29}$ Idem, 26/7/1930, p. 5.
} 
la mencionada compañía, recabando la solidaridad de todos los organismos gremiales del país, como también del pueblo de la república. ${ }^{30}$

La Fabril se negaba a mantener el salario correspondiente a 44 horas semanales para las secciones insalubres del gremio. Reclutaron entonces algunos carneros que aceptaran las condiciones. Pero la solidaridad del movimiento obrero frustró sus planes. El último cuarto del año culminó la huelga. Luego de un extenso lapso, en octubre el Departamento de Higiene se pronunció sobre la situación. Primero, desestimó el estudio de la patronal. Sostenía que "no es posible en manera alguna sacar conclusiones generales. Cinco talleres gráficos estudiados en una ciudad en que hay alrededor de 400; 83 obreros en una industria en que trabajan muchos millares, no justifican absolutamente la conclusión de que en general, tales trabajos no sean insalubres". Gregorio Aráoz Alfaro, director de la dependencia, concluía:

[...] no puede ponerse en duda el carácter de insalubridad de las profesiones u oficios implicados en el artículo 6 de la reglamentación. [...] el peligro de intoxicación crónica subsiste. [...] este Departamento opina que todos los obreros que trabajan en la industria de imprenta (linotipistas, monotipistas, tipógrafos, obreros de rotograbado, fotograbado, aerografía, etc.) deben ser incluidos como ejerciendo una profesión insalubre. Es tan evidente que los tipógrafos deben entrar en lo que la reglamentación de la ley dice 'manipulación de plomo, antimonio y estaño', que me parece absolutamente innecesario insistir en argumentos para probarlo. ${ }^{31}$

Fracasó de esta manera un intento patronal. El Departamento del Trabajo expidió la resolución al día siguiente. Ratificó la insalubridad con la necesidad de respetar los salarios. Frente a esta resolución y con el fracaso de sus tentativas los industriales debieron atenerse (al menos formalmente) a la medida.

Durante noviembre y diciembre la consigna del sindicato pasó a ser la reincorporación de los obreros que habían participado en la huelga. Los industriales retrasaban su reincorporación para poder burlar las tarifas con mayor facilidad, a pesar de la resolución oficial. A su vez, infringían la ley en cuestión: en estos dos meses el sindicato contabilizó 36 empresas en infracción (incluso dependencias estatales como la imprenta del Ministerio de Agricultura). En

\footnotetext{
${ }^{30}$ Idem, 22/8/1930, p. 5. Los productos boicoteados fueron el aceite Mandiyú, los fósforos Fiamma y Victoria y los naipes Angelito.

${ }^{31} \mathrm{BDNT}, \mathrm{n}^{\mathrm{o}}$ 152-3-4, octubre-noviembre-diciembre de 1930, pp. 3331-32. Agregaba a continuación una lista de estudios sobre salud laboral en diferentes países de Europa. Las declaraciones de Gregorio Aráoz Alfaro en La Vanguardia, 20/10/1930, p. 4.
} 
Damián A. Bil, Proceso de trabajo y luchas obreras en los años’30: los trabajadores gráficos,

Izquierdas, 30, Octubre 2016: 65-88

diciembre los últimos industriales reticentes aceptaron el dictamen $\mathrm{y}$ reincorporaron a los obreros, algunos por tandas alegando disminución del trabajo. En definitiva, la huelga duró 6 meses y afectó a más de 3.000 operarios. La reivindicación principal era la mejora de las condiciones y el mantenimiento del salario. Aclaremos que con la reducción de la jornada no se impedía la intoxicación. Solamente se lentificaba el proceso de la enfermedad.

Luego de este conflicto no se produjeron grandes acciones durante seis años. Los conflictos laborales se desarrollaron por establecimientos, como resume la tabla 1.

Tabla 1. Detalle de conflictos informados, industria gráfica, 1930-1940

\begin{tabular}{|c|c|c|c|}
\hline Establecimiento & Fecha & Motivo & Resultado \\
\hline Muschkat y Zaslavsky & Ene-30 & Condiciones & $\mathrm{s} / \mathrm{d}$ \\
\hline De Wart & Ene-30 & Maltratos & $\mathrm{s} / \mathrm{d}$ \\
\hline Femenil & Ene-30 & Salarios & Triunfo \\
\hline $\begin{array}{l}\text { Hays Bell y Cía., Soc. Impresora } \\
\text { Americana, Isidoro Moggio }\end{array}$ & Mar-30 & Salarios / Despido de activista / Otras & $\mathrm{s} / \mathrm{d}$ \\
\hline [Varias casas] & Jul-30 & Salarios / Violación ley 11.544 & Triunfo \\
\hline Ministerio Agricultura & Nov-30 & Despido injustificado & $\mathrm{s} / \mathrm{d}$ \\
\hline Ministerio de Guerra & Dic-30 & Violación jornada & $\mathrm{s} / \mathrm{d}$ \\
\hline Pedemonte & Ene-31 & Violación ley 11.544 & Triunfo \\
\hline Femenil & Mar-31 & Quiebra de empresa & $\mathrm{s} / \mathrm{d}$ \\
\hline Fabril Financiera & Mar-32 & Violación ley 11.544 & $\begin{array}{l}\text { Casa multada } \\
\text { por DNT }\end{array}$ \\
\hline $\begin{array}{l}\text { Capello Hnos., El Avisador } \\
\text { Mercantil, Abruzzin, Gadola, } \\
\text { Juan Kidd, Viola, }\end{array}$ & Mar-32 & Violación ley 11.544 & $\begin{array}{l}\text { Acta de } \\
\text { advertencia } \\
\text { DNT }\end{array}$ \\
\hline Fabril Financiera & Abr-32 & $\begin{array}{l}\text { Despido de activista / Violación ley } \\
11.544\end{array}$ & $\mathrm{~s} / \mathrm{d}$ \\
\hline Ministerio de Agricultura & Abr-33 & Despido injustificado & $\mathrm{s} / \mathrm{d}$ \\
\hline Cía. Impresora Argentina & May-33 & Despido de activista & Triunfo \\
\hline Hays Bell y Cía. & Abr-35 & Otras & $\mathrm{s} / \mathrm{d}$ \\
\hline [Varias casas] & Oct-36 & Salarios & Triunfo \\
\hline José Gaglianone & Dic-36 & Salarios & $\mathrm{s} / \mathrm{d}$ \\
\hline Acevedo y Petrone & Jul-37 & Salarios & $\mathrm{s} / \mathrm{d}$ \\
\hline Italo Nápoli & Oct-37 & Atraso en paga & Triunfo \\
\hline $\begin{array}{l}\text { Tomás Oucinde, Hays Bell y } \\
\text { Cía., Noticias Gráficas }\end{array}$ & Mar-38 & Despido injustificado / Atraso en paga & Triunfo \\
\hline G. Kraft Ltda. & Mar-39 & Violación ley 11.544 & $\mathrm{~s} / \mathrm{d}$ \\
\hline $\begin{array}{ll}\text { Lorenzo J. Rosso, } \\
\text { Argentinisches Tageblatt }\end{array}$ & Mar-39 & Condiciones / Violación jornada & $\mathrm{s} / \mathrm{d}$ \\
\hline
\end{tabular}

Fuente: elaboración propia partir de información relevada de La Vanguardia y El Obrero Gráfico, ediciones entre 1930 y 1940.

A medida que avanzaba la década, el costo de vida aumentó, según el Departamento del Trabajo. Pero los salarios no lo hicieron en la misma medida. El senador socialista Mario Bravo, a fines de 1936, expresaba: 
[...] la situación de los trabajadores ha empeorado considerablemente, a tal punto que lo van a apreciar los señores senadores cuando conozcan las cifras vigentes en el año 1928/29 y las que rigen en agosto del año actual, [...] facilitadas por la secretaría de la Federación Gráfica Bonaerense. Los encuadernadores, por ejemplo, en 1928/29 ganaban $\$ 9,20$ y este año, en agosto, ganan $\$ 6,16$. Los maquinistas ganaban $\$ 11,60$ y ahora ganan $\$ 8,16$. Los linotipistas ganaban $\$ 12,40$ y ahora $\$ 10,14$. Los tipógrafos ganaban $\$ 9,60$ y ahora $\$ 6,50$. Atribuyendo a las cifras de 1928/29 el valor de índice, resulta que los salarios de agosto del año actual tienen con relación a los salarios de 1928/29, los siguientes índices: 66,96, 70,34, 81,77 y 68,13, de donde se infiere que la retribución ha disminuido para los encuadernadores en un 33,04\%, para los maquinistas en un $29,66 \%$, para los linotipistas en $18,23 \%$ y para los tipógrafos en un 31,87 por ciento. ${ }^{32}$

En septiembre de ese año la Federación Gráfica decidió presentar un pliego de condiciones cuyo eje era el aumento salarial. A fines de mes, una asamblea de 5.000 gráficos en el teatro Marconi aprobó el pliego, que se presentó a comienzos de octubre. Algunos industriales decidieron enfrentar la medida. Al día siguiente de la presentación, la Fabril Financiera despidió a 150 obreros, todos afiliados al sindicato. Como la patronal no respondiera, los trabajadores en asamblea confirmaron el paro general, que comenzó el 21 de octubre. ${ }^{33}$ A los pocos días, una gran cantidad de firmas aceptó el aumento y sus planteles retornaron al trabajo. A fin de mes, solo "un pequeño grupo de industriales reaccionarios" continuaba en conflicto, como la casa Rosso y algunas encuadernaciones. Su resistencia fue corta, acordando el aumento a los pocos días. Esta fue la última de las grandes acciones del gremio en el período.

\section{5- Conclusiones}

Hemos analizado los principales cambios del proceso de trabajo y las acciones de los gráficos en la década, concentrándonos en el conflicto por insalubridad de 1930. Es momento de recapitular los principales elementos. En primer término consideramos que durante la década de 1930 se profundizó el régimen de gran industria. Nuevos equipos se incorporaron en las tareas, movimiento más agudo en las empresas líderes. Ello facilitó un incremento de la producción y permitió la expansión del sector. A su vez incentivó la descalificación de los trabajadores al simplificar las tareas necesarias en todas las secciones, lo que

32Diario de Sesiones de la Honorable Cámara de Senadores, 15/12/36, pp. 227-31.

${ }_{33}^{3}$ Información en La Vanguardia, 28/9/1936, p. 4., y 19/10/1936, p. 5. 
posibilitó la instalación de facto de la polifuncionalidad y de la rotación, con la violación del sistema de categorías. Al disminuir el entrenamiento requerido, permitió el ingreso de trabajadores con menor calificación. Cuando el aprendizaje se volvió ineficaz como herramienta de control del acceso al gremio, los industriales ocuparon otras fracciones de la clase como mujeres y niños a quienes pagaban un salario menor. En relación a la estructura de la clase, consideramos que los cambios tendieron a homogenizarla. La pérdida de conocimientos necesarios, el empleo de mujeres y niños incluso en las mismas tareas que los varones adultos y otros elementos analizados empujaban en el sentido de disolver las diferencias jerárquicas.

El sindicato se esforzó por agrupar al conjunto de los obreros en esta coyuntura subrayando reivindicaciones comunes como "igual salario para igual tarea" para varones y mujeres, condiciones generales, etc. Los obreros organizados incentivaron de esta forma la sindicalización de mujeres y niños, no sin contradicciones internas como hemos advertido. Ante las consecuencias de la mecanización el sindicato, por su propio carácter corporativo, no podía hacer mucho más que retrasar sus efectos. Por ello en las fuentes relevadas encontramos varios lamentos por la "racionalización capitalista", la intensificación de las tareas y otros resultados del proceso en cuestión. En ocasiones, los industriales sacaban partido de esta nueva situación. Violaban ciertas cláusulas del convenio como el régimen de categorías, la tarifa o la fijación a un puesto específico. La Federación Gráfica adoptó en estas situaciones una posición de denuncia, elevando informes ante del Departamento del Trabajo. En algunos casos aconsejó el sabotaje o el trabajo a desgano. Ello contrastó con su actitud más enérgica en períodos anteriores. Consideramos que esta posición se debe, por un lado, a los efectos de los cambios en el proceso de trabajo. Estas transformaciones provocaron un avance del capital sobre el trabajo. Los trabajadores perdieron posiciones (proceso que se remonta por lo menos a principios de siglo), y el sindicato vio acotado su margen de acción. Asimismo, hay que considerar que durante estos años el Partido Socialista ocupó los puestos directivos de la Federación Gráfica. Este partido se inclinaba en situaciones de conflicto hacia la negociación antes que hacia el recurso de huelga, lo que influyó en las actitudes frente a los conflictos.

No obstante, estos factores no impidieron que se produjeran movimientos huelguísticos, incluso generales. En efecto, observamos en el período algunas huelgas parciales (sobre todo luego de 1933) y dos conflictos generales de importancia: la huelga de 1930, relacionada con transformaciones en el proceso de trabajo y la más acotada de 1936 en reclamo de mejoras salariales. En cuanto a la primera, luego de seis meses de paro consiguieron el reconocimiento de la ley en las secciones donde se operaba con plomo. Esta, junto con la huelga de 1936 por recomposición salarial, fue una de las acciones de carácter general asumidas por 
los gráficos en la década.

Las transformaciones en el proceso de trabajo de los años previos contribuyeron a que la relación de fuerzas se inclinara cada vez más hacia el lado de los industriales. Cuando la situación se los permitía, avanzaron sobre las condiciones laborales. El sindicato intentó todas las respuestas, en el siguiente orden: negociación, denuncia, quita de colaboración, huelga parcial y finalmente huelga general. La situación de 1930 ejemplifica esta realidad. En esta ocasión la organización obrera pudo, mediante la huelga y la solidaridad gremial, conseguir un leve paliativo ante las consecuencias de las transformaciones en el proceso de trabajo.

\section{Bibliografía}

Argentina Gráfica, Bs As, varios años.

Anales Gráficos, Bs As, varios años.

Badoza, Silvia: "Patrones, capataces y trabajadores en la industria gráfica. Un estudio de caso: Ortega y Radaelli, 1901-1921”. Revista Secuencia, n 50, México, mayo-agosto 2001.

Badoza, Silvia: “Typographical Workers and their Mutualist Experience: The Case of the Sociedad Tipográfica Bonarense, 1857-80", en Adelman, Jeremy (comp.): Essays in Argentine Labour History, 1870-1930. Londres, Macmillan Press, 1992.

Badoza, Silvia y Tato, María Inés: “Trabajadores y empresarios gráficos en la coyuntura crítica de 1919". X Jornadas Interescuelas Departamentos de Historia, Universidad Nac de Rosario, septiembre de 2005.

Bil, Damián: Descalificados. Proceso de trabajo y clase obrera en la industria gráfica en Buenos Aires (1880-1940). Bs As, Ediciones ryr, 2007.

Chueco, Manuel. Los Pioneers de la industria nacional. Buenos Aires, Imprenta de La Nación, 1886.

Contreras, Gustavo: “La huelga de los obreros gráficos, 1949”. I Jornadas Jóvenes Investigadores, Universidad Nac de Mar del Plata, junio de 2007.

El Obrero Gráfico (órgano de la Federación Gráfica Bonaerense). Varios números.

Ferrer, Nelson: Historia de los gráficos argentinos. Bs As, Dos Orillas, 2008 
Guindi, Leticia: “La huelga de los trabajadores gráficos en 1949. Análisis particular de un conflicto gremial durante el peronismo". IX Jornadas Interescuelas de Historia, Córdoba, 2003.

La Nación, diario comercial de circulación masiva, varios años.

La Vanguardia, órgano del Partido Socialista de aparición diaria, varios años.

La Nación: Un siglo en sus columnas. Buenos Aires, La Nación, enero de 1970.

Ugarteche, Félix. La imprenta argentina (1700-1929). Bs As, Talleres Canals, 1929.

Documentos públicos

Barret, Robert. Paper, paper products and printing machinery in Argentina, Uruguay and Paraguay. Special Agents Series $N^{0}$ 163, Washington, Dept. of Commerce, 1918.

Boletín del Departamento Nacional del Trabajo (BDNT), varios números.

Censo General de Población, Edificación, Comercio e Industrias de la Ciudad de Buenos Aires. Bs As, Cía. Sudamericana de Billetes de Banco, ago-sep de 1887.

Censo General de Población, Edificación, Comercio e Industrias de la Ciudad de Buenos Aires. Bs As, Cía. Sudamericana de Billetes de Banco, 1910.

Diario de Sesiones de la Honorable Cámara de Senadores, 15/12/1936.

Tercer Censo de la República (1914). Buenos Aires, Talleres Gráficos Rosso, 1916-17.

$\underline{\text { Entrevistas }}$

Entrevista a A.C., ex doblador, febrero de 2007, en poder del autor.

Entrevista a A.N., ex impresor de taller pequeño, 19/03/2007, en poder del autor. 